Research Article

\title{
Effect of Tea Waste on Cracking of Foundation Soil
}

\author{
Binbin Yang $\left(\mathbb{D},{ }^{1}\right.$ Zepeng Zhang $\left(\mathbb{D},{ }^{1}\right.$ Wenlong $\mathrm{Ma}\left(\mathbb{D},{ }^{1}\right.$ Mingming $\mathrm{Hu}(\mathbb{D}){ }^{1}$ \\ and Yaning Zhang $\mathbb{D}^{2}$
}

${ }^{1}$ School of Civil Engineering, Xuchang University, Xuchang, China

${ }^{2}$ China Coal Research Institute, Beijing 100013, China

Correspondence should be addressed to Binbin Yang; yangbinbin@xcu.edu.cn

Received 15 November 2021; Accepted 26 November 2021; Published 9 December 2021

Academic Editor: Yonghong Wang

Copyright (C) 2021 Binbin Yang et al. This is an open access article distributed under the Creative Commons Attribution License, which permits unrestricted use, distribution, and reproduction in any medium, provided the original work is properly cited.

Desiccation cracks form on the surface of foundation soils due to matric suction and surface shrinkage with water loss. This paper investigates the effect of tea waste on the change of water content and cracking characteristics of foundation soil during drying. Digital image processing was carried out based on laboratory experiments. The characteristics are monitored with a variation in water content. The effects of different amounts of tea waste on soil drying and cracking were obtained, in order to provide an efficient and new green sustainable material for improving soil evaporation cracking under drought conditions. The results show that the development of cracks of soil samples with tea waste can be categorized into three stages in accordance with the fractal dimension of the desiccation cracks: Stages I, II, and III. The desiccation cracks in Stage III are wider and longer than those in Stages I and II, however, the maximum fractal dimension and stability are also obtained in Stage III. The residual water content of the sample without tea waste is $1.5 \%$. The residual water content of the samples containing $4 \%$ and $8 \%$ tea waste is $4.6 \%$ and $5.4 \%$, respectively, which shows that the tea waste can effectively improve the residual water content of the foundation soil and the water holding capacity of the soil. The fractal dimension of cracks on the soil samples increases gradually with drying. The total length of cracks increases and the development of cracks is more complex. The cracking time of soil samples with different tea waste contents is different. The soil samples with $8 \%$ tea waste content crack first. Combined with the variation characteristics of water content, tea waste has water absorption and improves the water holding capacity and stability of foundation soil.

\section{Introduction}

Soil moisture evaporation is one of the main processes of soil atmosphere material and energy exchange, and it is also an important part of surface heat and water balance. For the soil in nature, the driving force of evaporation comes from climate, especially arid climate $[1,2]$. As evaporation will change the content and distribution of water in soil, resulting in changes in the engineering properties of soil, many engineering and environmental problems are directly or indirectly related to evaporation $[3,4]$. The problem of soil water evaporation involves many disciplines, such as geology, geotechnical, water conservancy, road, environment, and atmosphere $[5,6]$. Especially in recent years, affected by global climate change, extreme arid climate occurs frequently, related disasters are becoming more and more prominent, and economic losses are becoming more and more huge $[7,8]$.
For example, under the action of evaporation, the soil will shrink and deform, causing land settlement and damaging the infrastructure on the ground [9-11].

Under drought conditions, due to evaporation and water loss, soil is prone to dry shrinkage cracking, and a crisscross crack network is formed on the surface. Soil dry shrinkage cracking is very common in nature [12-14]. The existence of cracks will destroy the integrity of soil, make its structure loose and reduce its mechanical properties, and then cause various engineering geological problems $[15,16]$. For example, soil cracking is one of the key factors affecting the stability of foundation soil. While destroying the integrity of soil, it will also weaken the structure of soil and provide convenient conditions for the infiltration of rainwater. When cracks occur, the shear strength of soil and the safety factor of the foundation will decrease greatly, inducing the occurrence of foundation settlement disaster [17-19]. In slope engineering, cracks will provide a convenient channel for rainwater to infiltrate into the 
soil. And the shear strength of the soil will be reduced, which will lead to slope instability and also may lead to the increase of landslide and other projects, resulting in the sharp weakening of its barrier function [20-22]. In hydraulic engineering, cracks will form a preferential diversion channel in the soil embankment, increasing the permeability and reducing the strength of the dam, and threatening the stability of the dam [23-25]. Therefore, the study of soil shrinkage cracking is of great significance to prevent engineering and environmental geological problems in arid climate environment.

The drying and cracking of clay are closely related to the shrinkage of soil. The stronger the shrinkage of soil, the easier it is to produce drying and cracking. The shrinkage is controlled by the type and content of clay minerals in soil $[26,27]$. The development process of cracking of soil under natural environmental conditions has been studied by many scholars. And the changes of some basic physical quantities such as suction, water content, and temperature with time and their distribution in soil have been detected $[28,29]$. The problem of soil drying and cracking involves many fields and a wide range. In order to prevent the drying and cracking of engineering soil, it is necessary to carry out systematic research on the key scientific problems such as the causes, development laws, and mechanisms of drying and cracking. Selecting appropriate research methods is an important premise to solve the above key scientific problems [30]. Tea waste is a very green, lowcost, and effective adsorbent, which can be used to remove various impurities in water [31]. In recent years, abandoned tea has been widely used in engineering $[32,33]$. Savas ozturk and Mucahit Sutcu added different concentrations of tea waste into clay mixture to study their effects on the properties of sintered brick. The results show that bricks with high porosity can be produced by using tea waste [34].

Sadam Hussain Jakhrani and Hong Gi Kim studied the control effect of black tea waste and perlite on the rapid heat of early hydration of high-strength cement mortar. The curing effects of tea waste and perlite at different ratios were studied. The results show that the samples prepared with coarse tea waste and perlite are more conducive to controlling early rapid hydration than those prepared with fine particles. After chemical activation, tea waste can be used as an adsorbent for harmful metal ions in wastewater [35].

In this paper, a scheme of using tea waste to improve the foundation soil is proposed. In order to study the influence of this technology on the evaporation characteristics and crack development characteristics of the improved foundation soil, a series of evaporation tests is carried out on the tea waste improved soil, and the drying and cracking characteristics of the tea waste improved foundation soil are analyzed by using digital image processing technology. The influence law and mechanism of tea waste content on foundation soil evaporation and crack development are obtained.

\section{Materials and Methods}

\subsection{Materials}

2.1.1. Soil Samples. The soil sample used in this experiment is the foundation soil in the Yellow River Basin of Henan
Province, China $\left(113^{\circ} \mathrm{E}, 35^{\circ} \mathrm{N}\right)$. The appearance of the soil sample is light yellow, tasteless, and has no obvious inclusions. The climate of different regions in the basin is significantly different. In winter, affected by the dry and cold air flow from inland, the weather is cold, dry, and less rain. In summer, affected by the warm and humid air flow from the ocean, it is hot, humid, and rainy. The high temperature period is consistent with the rainy period, and the temperature is appropriate, which is very beneficial to the growth of crops.

Due to the high humidity of the soil sample, the soil sample shall be air-dried until it is easy to be crushed, and the soil sample shall be crushed by a wooden hammer. Then, the soil sample is dried in an electric oven at $105^{\circ} \mathrm{C}-110^{\circ} \mathrm{C}$, and the dried soil is then taken out. According to the quality of soil samples, the dried soil samples are filtered through a standard sieve with an aperture of $2 \mathrm{~mm}$, and then soil samples with a particle size of less than $2 \mathrm{~mm}$ were obtained. $200 \mathrm{~g}$ soil samples after screening are taken out and placed in multiple square containers to prepare for subsequent tests. The basic physical properties of natural soil samples measured in the test are shown in Table 1.

2.1.2. Tea Waste. The tea waste used in this experiment is from the tea waste in daily life. In the past, the tea waste was often used as fertilizer for plant potting, but the decomposition cycle is long.The collected tea waste is dried until it becomes dry; then, the dried tea waste is crushed with a pulverizer; and the crushed tea waste powder is placed in a sealed container.

2.2. Experimental Process. In order to study the effect of tea waste content on the evaporation and cracking characteristics of soil samples, three groups of samples with different tea waste contents $(0 \%, 4 \%$, and $8 \%$ by weight) were designed, and two parallel tests in each group were compared with each other, as listed in Table 2. $200 \mathrm{~g}$ weighed soil sample and tea waste with different contents were poured into a square container. And an appropriate amount of water was added to the mixture so as to fully integrate the tea waste and soil sample. And then, water is added to mix it into a saturated slurry with a water content of $150 \%$, as shown in Figure 1 . In order to completely precipitate the sample, the soil sample was sealed for 48 hours. Then, the sample is placed on the electronic balance, and it naturally dried at room temperature of $25^{\circ} \mathrm{C}$ to lose water. In the display screen of the electronic balance, the mass of the sample can be read in real time, and then the change of the water content of the sample can be obtained. In order to obtain the cracking characteristics of the sample during evaporation, the sample is weighed every 3 hours, and the time recorded before the sample is cracked. After the sample is cracked, it shall be weighed every 5 minutes and photographed directly above the sample with a digital camera to record the crack degree of the sample.

After the test, the recorded time, the mass of the square container, the total mass of the sample, the soil sample, and the crack image are imported into the computer to obtain the water content change data. 
TABLE 1: Physical properties of soil samples.

\begin{tabular}{lcccccc}
\hline \multirow{2}{*}{ Density $\left(\mathrm{g} / \mathrm{cm}^{3}\right)$} & Liquid limit & Plastic limit & Plasticity index & \multicolumn{3}{c}{ Particle distribution (\%) } \\
& 34.8 & 17.1 & 17.3 & Clay particle & Silt & Sand \\
\hline 2.74 & & & 58 & 10 \\
\hline
\end{tabular}

TABLE 2: Design parameters of evaporation test.

\begin{tabular}{lcc}
\hline No. & Tea waste content & Remarks \\
\hline 1 & 0 & Comparative experiment \\
2 & 0 & \\
3 & $4 \%$ & Comparative experiment \\
4 & $4 \%$ & Comparative experiment \\
5 & $8 \%$ & \\
6
\end{tabular}

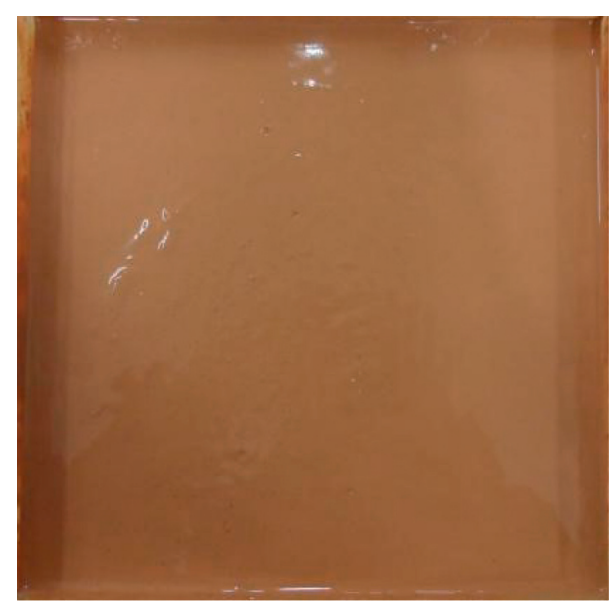

Figure 1: Saturated mud sample.

2.3. Digital Image Processing Technology. The crack image recorded by the digital camera is transmitted to the computer. After the required images are collected, the next step is to preprocess the images and remove some interference, which makes the crack information prominent so as to lay a good foundation for analyzing the numerical value of crack images. The image processing includes segmentation threshold, gray image, and median filtering. For each crack image, firstly, the image is cut to remove the boundary part of the image and reduce the influence of boundary conditions. In order to exclude the boundary, the image was cut to a size of $16 \times 16 \mathrm{~cm}$ which is the center of the digitally recorded image. Before calculating the parameters of the digital images, the crack images should be transformed into a binary image.

A large amount of color information is included in the crack image information, which is very unfavorable to the calculation of crack image. Gray image is expressed by brightness, and the same gray is usually divided into 256 levels [36]. The numbers from 0 to 255 are used to represent colors, respectively. The darkest one is represented by 0 , that is, black. The brightest one is represented by 255 , that is, white. The remaining numbers are used to represent the numbers between 0 and 255. In this case, only one parameter is left for each pixel, and an image can be represented by a two-dimensional matrix. The three parameter values of each pixel of the color image are $R, \mathrm{G}$, and $\mathrm{B}$. The effect of converting a color image into a gray image is shown in Figure 2(b). After the color image converts the crack image into a gray image, the image has only a very small loss, and the crack is clearer. Selecting an appropriate threshold, that is, the gray value, is to effectively compare the gray level of each pixel with the threshold. If the pixel gray level is greater than the threshold, the gray level becomes 255. If the pixel gray level is smaller than the threshold, the gray level becomes 0. As shown in Figure 2(c), after the image is binarized by threshold segmentation, only white and black are left in the image, and the crack can be obviously separated from the background. Selecting the threshold is an important part of dividing the image into binary images, and the accuracy of identifying the edge of the crack image is directly affected by it [37].

After binary processing of the image, there are still large and small noise in the background, and the crack edge is still unclear. Therefore, it is necessary to deeply process the image denoising. The value filter is effectively used to denoise the crack image [38]. The median filter belongs to the lowpass filter. The pixels in the field can be arranged according to the gray level, and the intermediate value can be taken out as the output object so that the image edge can be effectively protected. Not only the noise should be controlled well but also the edge should be clear and not blurred. The median filter needs to select a sliding window, and the containing points need to be odd. The gray value of each point in the window is used to replace the specified points, usually the center point of the window. After the median filter, if the discretely separated noise still exists, using manual erasure, the final image is shown in Figure 2(d).

Finally, box counting is used to calculate the fractal dimension of the crack image [39]. A small box is taken with side length $r$ and the fractal curve is curved. Then, some small boxes are empty, and some small boxes the cover part of the curve. The number of boxes covering cracks obtained is recorded as $N(r)$. Then, the size of the box is reduced, and the resulting $N(r)$ naturally increases. When $r \longrightarrow 0$, the fractal dimension is obtained as follows:

$$
D=-\lim _{r \longrightarrow 0} \frac{\log N(r)}{\log r} .
$$

In the actual calculation, only a limited $r$ can be taken. The usual method is similar to the size method. a series of $r$ and $N(r)$ is found, and then the least square method is used to fit the straight line in the double logarithmic coordinates. The slope of the straight line is the calculated fractal dimension.

\section{Results}

3.1. Effect of Tea Waste on Soil Water Content. Figure 3 shows the variation characteristics of sample water content under 


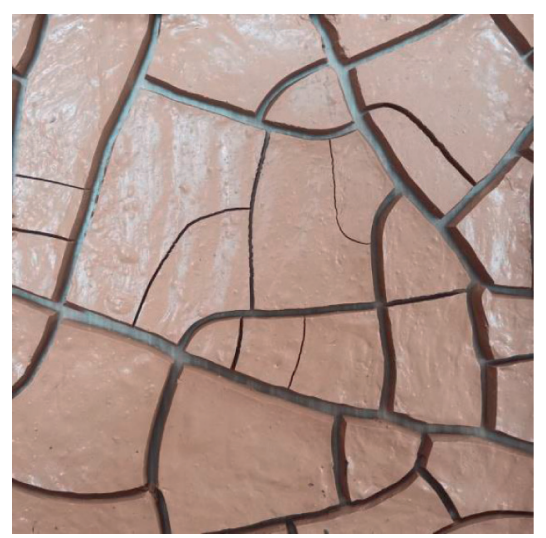

(a) Original image

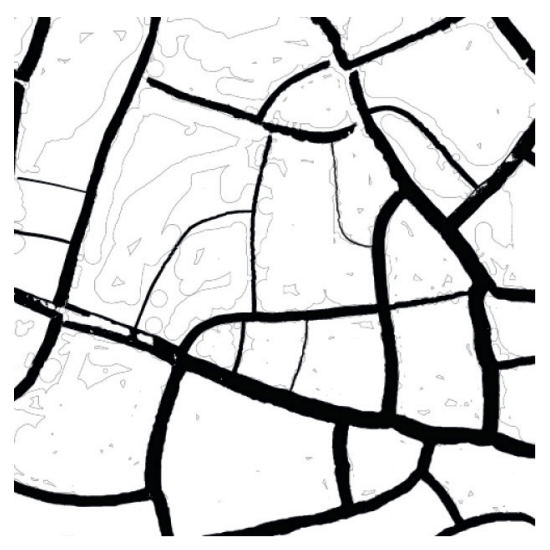

(d) Filter denoising

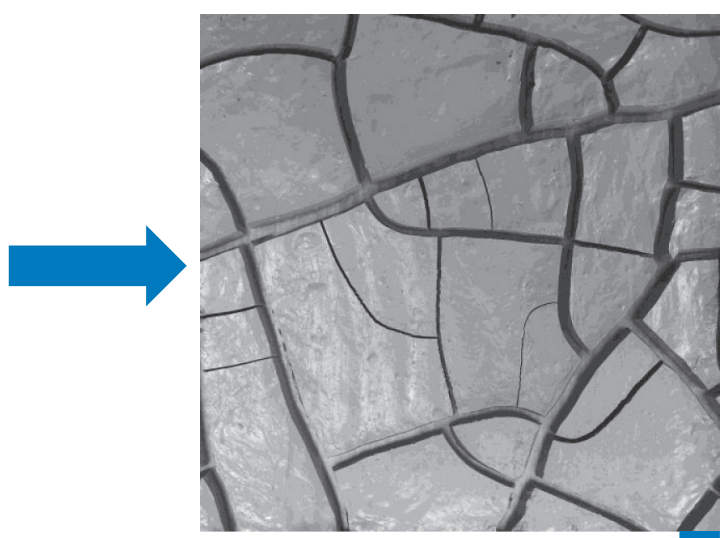

(b) Grayscale image

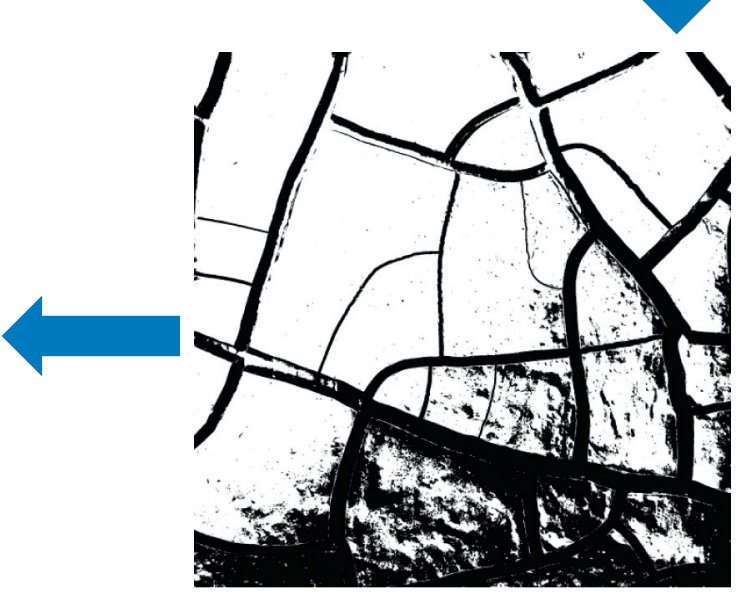

(c) Binary image

FIGURE 2: Image processing process.

different tea waste contents. The soil sample is made into supersaturated sample by adding excess water. With the change of water content, firstly, the water on the soil surface begins to evaporate. This part is free water, which leads to rapid evaporation. As shown in Figure 3, the slope of the curve is relatively large. When the sample evaporates to $84 \mathrm{~h}$, the water content of the sample gradually tends to be stable. At this time, the remaining water content of the sample is called the residual water content. At this time, the surface of the sample is in equilibrium, the evaporation and absorption of water in the air are in equilibrium, and the water content of the sample basically does not change. The residual water content of the sample without tea waste is $1.5 \%$, and the residual water content of the sample with $4 \%$ and $8 \%$ tea waste is $4.6 \%$ and $5.4 \%$, respectively, which shows that tea waste can effectively improve the residual water content of soil and the water holding capacity of soil.

In the evaporation process, the soil sample without tea waste reached equilibrium at $82 \mathrm{~h}$, and the water content of the soil sample did not change, reaching the residual water content. The soil sample containing $4 \%$ tea waste reached equilibrium after $86 \mathrm{~h}$, and the water content of the soil sample did not change but also reached the residual water content. The soil sample containing $8 \%$ tea waste reaches the equilibrium state after $106 \mathrm{~h}$, and the water content of the soil sample does not change. At this time, it also reaches the residual water content. The tea waste with $8 \%$ content can effectively improve the water holding capacity of the soil and effectively inhibit the evaporation of the soil under dry conditions, which has an important impact on the stability of the engineering soil under dry conditions.

3.2. Effect of Tea Waste on Soil Cracking. Figure 4 shows the volume shrinkage of the soil caused by water loss during the evaporation process of the sample, resulting in cracking. The soil cracks have an important impact on the stability of the project. Figure 4 shows that the drying crack of soil sample has experienced the development process of three-level crack. The first-level crack is also called the main crack, and this crack developed first. As the water evaporates, the volume of the soil sample shrinks, and the secondary cracks begin to develop. The secondary cracks are mainly the branches of the primary cracks. As shown in Figure 4, the secondary cracks begin to develop near the primary cracks. With the progress of drying, the soil volume continues to 


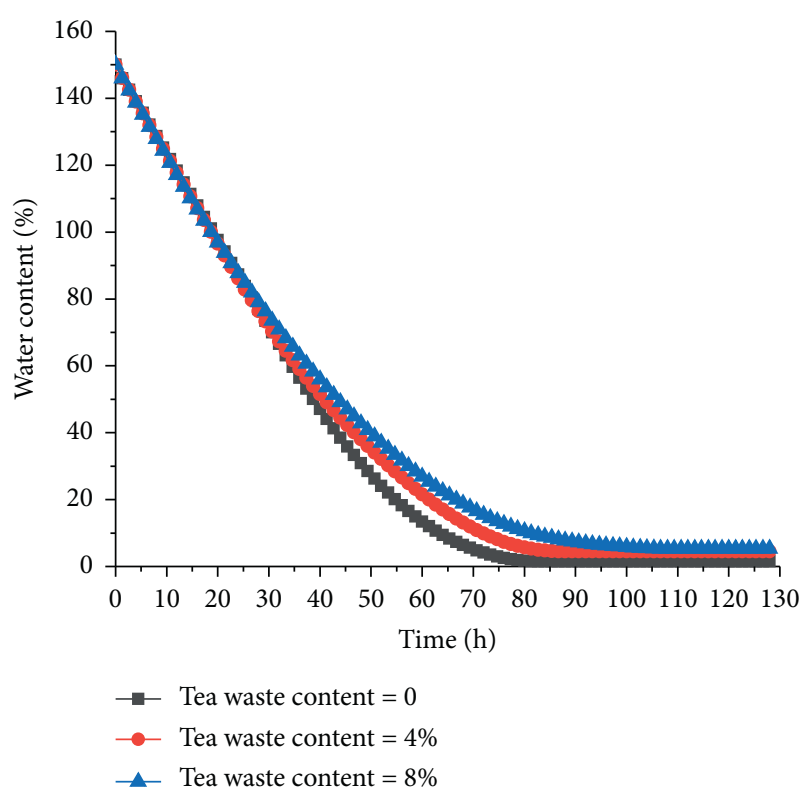

FIGURE 3: The water content versus different tea waste contents of samples.

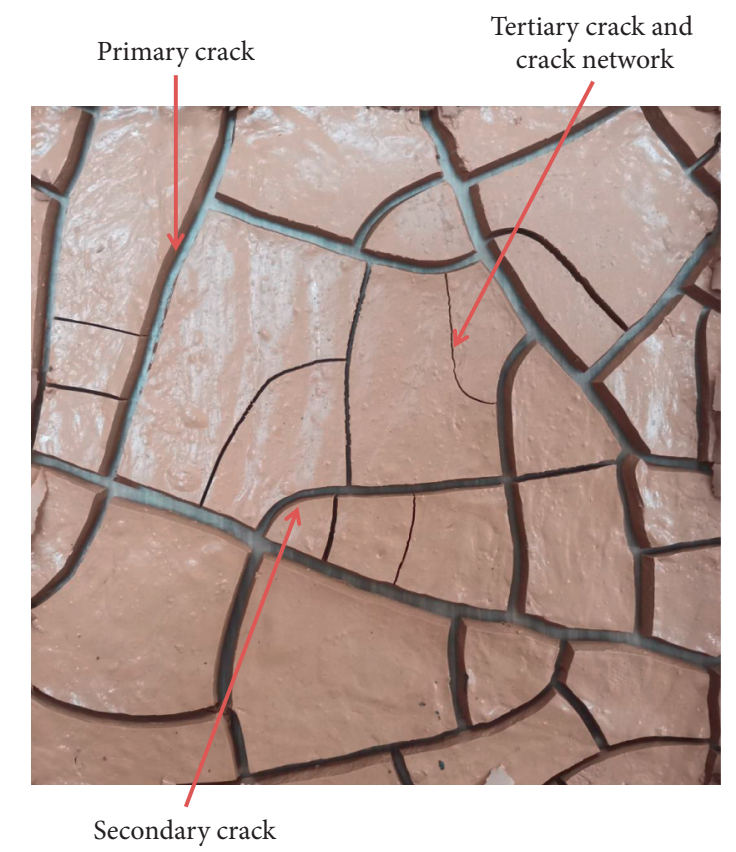

FIGURE 4: Tertiary crack development of sample.

shrink, and the secondary cracks begin to develop, like the strut of the "tree". After continuous evaporation and drying, the third-order cracks begin to appear, and intersect with the second-order cracks and the first-order cracks, and finally form a crack network. After cracking, evaporation is promoted and soil drying is accelerated.

The crack development on the surface of the soil sample is calculated, and the variation characteristics of the fractal dimension of the crack surface are obtained, as shown in Figure 5. In the process of drying, the fractal dimension of cracks increases gradually with the progress of drying,

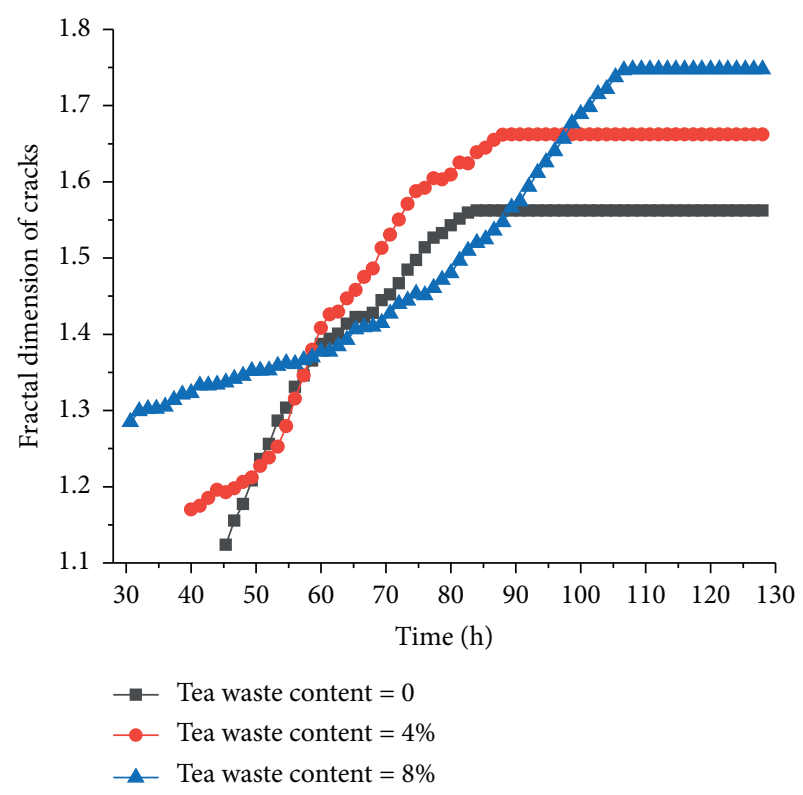

FIGURE 5: The fractal dimension of cracks versus different tea waste contents.

indicating that the total length of cracks increases and the development of cracks is more complex. The development of cracks of soil samples with tea waste can be categorized into three stages in accordance with the fractal dimension of the desiccation cracks. The desiccation cracks in Stage III are wider and longer than those in Stages I and II; however, the maximum fractal dimension and stability are also obtained in Stage III. The cracking time of soil samples with different tea waste contents is different. The soil samples with $8 \%$ tea waste content crack first. Combined with the change characteristics of water content, tea waste has the ability to absorb water and maintain a certain amount of water, which leads to the loss of water in the soil first. Finally, with the increase of tea waste concentration, the cracking time of soil samples is advanced, and the final crack network is formed. The complexity of the crack network with $8 \%$ tea waste content is greater than that of soil samples with $4 \%$ tea waste and without tea waste. However, according to the change of curve slope in the figure, the cracking rate of soil samples with $8 \%$ tea waste content is lower than that of soil samples with $4 \%$ tea waste and without tea waste, which shows that the fractal dimension of soil samples with $8 \%$ tea waste content increases slowly.

\section{Discussion}

When the water content reaches $18 \%$, the shrinkage begins to slow down, and residual contraction takes place. At this time, water escapes from the pores of the soil structure. The fractal dimension and rate of cracking are also reduced. Finally, the water content remains unchanged at about $6 \%$, while in the soils, there is a loss of free, capillary and weakly bound water, and shrinkage stops. The average width of the cracks is first increased and then decreased, and the length of the cracks continued to grow. 


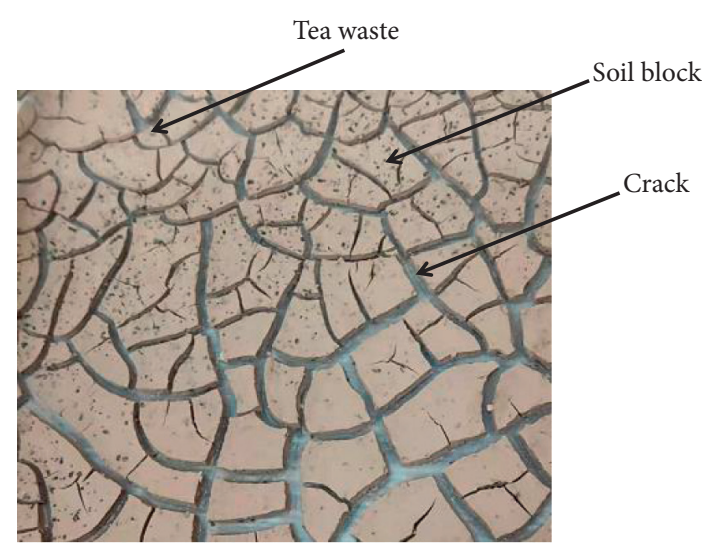

FIGURE 6: Drying and cracking of tea waste mixed with soil.

Based on the above results and the changes of water content and crack development characteristics of soil samples with different tea waste contents, the mechanism of tea waste on improved soil evaporation cracking is simply discussed. As shown in Figure 6, after tea waste is mixed with soil, there is tea waste on the soil surface, which increases the color of soil sample, and may increase the soil sample temperature and promote water evaporation. As a result, the crack network of soil samples with more tea waste is more developed. In the later stage, tea waste and soil form soil polymer together. The water content in tea waste increases the water content in soil polymer, and the residual water content increases.

\section{Conclusion}

The basic physical properties of the soil samples are obtained in advance. The collected tea waste is simply processed as a soil modifier. Through the indoor drying test, the evaporation cracking characteristics of soil samples with different tea waste content are studied, and the effects of different tea waste contents on the water content of soil samples and the cracking characteristics of soil samples are obtained.

The residual water content of the sample without tea waste is $1.5 \%$, and the residual water content of the sample with $4 \%$ and $8 \%$ tea waste is $4.6 \%$ and $5.4 \%$, respectively, which shows that tea waste can effectively improve the residual water content of soil and the water holding capacity of soil. The drying and cracking of the soil sample have experienced the development process of three-level cracks. The first-level crack is also known as the main crack, which developed first. With the evaporation of water, the volume of soil sample shrinks, and the secondary cracks begin to develop. The secondary cracks are mainly the branches of the primary cracks. In the process of drying, the fractal dimension of cracks increases gradually with the progress of drying, indicating that the total length of cracks increases and the development of cracks is more complex. The cracking time of soil samples with different tea waste contents is different. The soil sample with $8 \%$ tea waste content cracks first. Combined with the change characteristics of water content, tea waste has the ability to absorb water and maintain a certain amount of water, which leads to the loss of water in the soil first.

\section{Data Availability}

The datasets generated during the current study are available from the corresponding author on reasonable request.

\section{Conflicts of Interest}

No conflicts of interest exist in the submission of this manuscript

\section{Acknowledgments}

The authors would like to acknowledge the Scientific Research Innovation Team of Xuchang University. This work was supported by the Henan College Students' innovation and entrepreneurship training program (grant no. S202110480034), the Strategic research and consulting project of Chinese Academy of Engineering (grant number 2021-XY-26), and the Henan Key Scientific Research Projects of Colleges and Universities (grant nos. 21A410003 and 22B570002).

\section{References}

[1] K. R. Wythers, W. K. Lauenroth, and J. M. Paruelo, "Bare-soil evaporation under semiarid field conditions," Soil Science Society of America Journal, vol. 63, no. 5, pp. 1341-1349, 1999.

[2] R. C. Schwartz, R. L. Baumhardt, and S. R. Evett, "Tillage effects on soil water redistribution and bare soil evaporation throughout a season," Soil and Tillage Research, vol. 110, no. 2, pp. 221-229, 2010.

[3] O. Merlin, V. G. Stefan, A. Amazirh et al., "Modeling soil evaporation efficiency in a range of soil and atmospheric conditions using a meta-analysis approach," Water Resources Research, vol. 52, no. 5, pp. 3663-3684, 2016.

[4] Y. Wan, C. Wu, Q. Xue, and X. Hui, "Effects of plastic contamination on water evaporation and desiccation cracking in soil," The Science of the Total Environment, vol. 654, pp. 576-582, 2019.

[5] R. Ragab, P. Rosier, A. Dixon, J. Bromley, and J. D. Cooper, "Experimental study of water fluxes in a residential area: 2. road infiltration, runoff and evaporation," Hydrological Processes, vol. 17, no. 12, pp. 2423-2437, 2003.

[6] H. D. Van Bohemen and W. J. Van de Laak, "The influence of road infrastructure and traffic on soil, water, and air quality," Environmental Management, vol. 31, no. 1, pp. 0050-0068, 2003.

[7] A. Dai, T. Zhao, and J. Chen, "Climate change and drought: a precipitation and evaporation perspective," Current Climate Change Reports, vol. 4, no. 3, pp. 301-312, 2018.

[8] R. N. Armstrong, J. W. Pomeroy, and L. W. Martz, "Variability in evaporation across the Canadian Prairie region during drought and non-drought periods," Journal of Hydrology, vol. 521, pp. 182-195, 2015.

[9] B. Yuan, Z. Li, Z. Zhao, H. Ni, Z. Su, and Z. Li, "Experimental study of displacement field of layered soils surrounding laterally loaded pile based on transparent soil," Journal of Soils and Sediments, vol. 21, no. 9, pp. 3072-3083, 2021.

[10] B. Y. Yuan, Z. H. Li, Z. L. Su, Q. Z. Luo, M. J. Chen, and Z. Q. Zhao, "Sensitivity of multistage fill slope based on finite element model," Advances in Civil Engineering, vol. 2021, Article ID 6622936, 13 pages, 2021. 
[11] B. Y. Yuan, Z. H. Li, Y. Chen et al., "Mechanical and microstructural properties of recycling granite residual soil reinforced with glass fiber and liquid-modified polyvinyl alcohol polymer - sciencedirect," Chemosphere, vol. 268, Article ID 131652, 2021.

[12] S. Bordoloi, J. Ni, and C. W. W. Ng, "Soil desiccation cracking and its characterization in vegetated soil: a perspective review," The Science of the Total Environment, vol. 729, Article ID 138760, 2020.

[13] H. Nahlawi and J. K. Kodikara, "Laboratory experiments on desiccation cracking of thin soil layers," Geotechnical \& Geological Engineering, vol. 24, no. 6, pp. 1641-1664, 2006.

[14] H. Peron, T. Hueckel, L. Laloui, and L. B Hu, "Fundamentals of desiccation cracking of fine-grained soils: experimental characterisation and mechanisms identification," Canadian Geotechnical Journal, vol. 46, no. 10, pp. 1177-1201, 2009.

[15] Y. L. Gui, Z. Y. Zhao, J. Kodikara, H. H. Bui, and S. Q. Yang, "Numerical modelling of laboratory soil desiccation cracking using UDEC with a mix-mode cohesive fracture model," Engineering Geology, vol. 202, pp. 14-23, 2016.

[16] T. D. Vo, A. Pouya, S. Hemmati, and A. M. Tang, "Numerical modelling of desiccation cracking of clayey soil using a cohesive fracture method," Computers and Geotechnics, vol. 85, pp. 15-27, 2017.

[17] H. Ding, Z. Li, J. Lian, P. Zhang, and X. Huang, "Soil reinforcement experiment inside large-scale bucket foundation in muddy soil," Transactions of Tianjin University, vol. 18, no. 3, pp. 168-172, 2012.

[18] B. A. Bradley, M. Cubrinovski, R. P. Dhakal, and G. A. MacRae, "Probabilistic seismic performance and loss assessment of a bridge-foundation-soil system," Soil Dynamics and Earthquake Engineering, vol. 30, no. 5, pp. 395$411,2010$.

[19] N. Zhou, P. A. Vermeer, R. Lou, Y. Tang, and S. Jiang, "Numerical simulation of deep foundation pit dewatering and optimization of controlling land subsidence," Engineering Geology, vol. 114, no. 3-4, pp. 251-260, 2010.

[20] A. Galeandro, A. Doglioni, V. Simeone, and J. Šimůnek, "Analysis of infiltration processes into fractured and swelling soils as triggering factors of landslides," Environmental earth sciences, vol. 71, no. 6, pp. 2911-2923, 2014.

[21] H. Xiao, J. Huang, Q. Ma et al., "Experimental study on the soil mixture to promote vegetation for slope protection and landslide prevention," Landslides, vol. 14, no. 1, pp. 287-297, 2017.

[22] J. Zhan, Q. Wang, W. Zhang, Y. Shangguan, S. Song, and J. Chen, "Soil-engineering properties and failure mechanisms of shallow landslides in soft-rock materials," Catena, vol. 181, Article ID 104093, 2019.

[23] J. D. Rice and J. M. Duncan, "Deformation and cracking of seepage barriers in dams due to changes in the pore pressure regime," Journal of Geotechnical and Geoenvironmental Engineering, vol. 136, no. 1, pp. 16-25, 2010.

[24] M. Foster, R. Fell, and M. Spannagle, "The statistics of embankment dam failures and accidents," Canadian Geotechnical Journal, vol. 37, no. 5, pp. 1000-1024, 2000.

[25] Y. Jia, B. Xu, S. Chi, B. Xiang, D. Xiao, and Y. Zhou, "Joint back analysis of the creep deformation and wetting deformation parameters of soil used in the Guanyinyan composite dam," Computers and Geotechnics, vol. 96, pp. 167-177, 2018.

[26] E. M Segal, L. Ramsburg, J. Draper et al., "Clay cracking: a natural process guiding a design-to-fabrication method for cast aluminum panels," Technology|Architecture + Design, vol. 4, no. 1, pp. 106-114, 2020.
[27] R. N. Tollenaar, L. A. Van Paassen, and C. Jommi, "Observations on the desiccation and cracking of clay layers," Engineering Geology, vol. 230, pp. 23-31, 2017.

[28] U. Chaduvula, B. V. S. Viswanadham, and J. Kodikara, "A study on desiccation cracking behavior of polyester fiberreinforced expansive clay," Applied Clay Science, vol. 142, pp. 163-172, 2017.

[29] C. S. Tang, Y. J. Cui, A. M. Tang, and B. Shi, "Experiment evidence on the temperature dependence of desiccation cracking behavior of clayey soils," Engineering Geology, vol. 114, no. 3-4, pp. 261-266, 2010.

[30] C. Tang, B. Shi, C. Liu, L. Zhao, and B. Wang, "Influencing factors of geometrical structure of surface shrinkage cracks in clayey soils," Engineering Geology, vol. 101, no. 3-4, pp. 204-217, 2008.

[31] B. M. W. P. K. Amarasinghe and R. A. Williams, "Tea waste as a low cost adsorbent for the removal of $\mathrm{Cu}$ and $\mathrm{Pb}$ from wastewater," Chemical Engineering Journal, vol. 132, no. 1-3, pp. 299-309, 2007.

[32] S. Guo, M. Kumar Awasthi, Y. Wang, and P. Xu, "Current understanding in conversion and application of tea waste biomass: a review," Bioresource Technology, vol. 338, Article ID 125530, 2021.

[33] C.-H. Weng, Y.-T. Lin, D.-Y. Hong, Y. C. Sharma, S.-C. Chen, and K. Tripathi, "Effective removal of copper ions from aqueous solution using base treated black tea waste," Ecological Engineering, vol. 67, pp. 127-133, 2014.

[34] S. Ozturk, M. Sutcu, E. Erdogmus, and O. Gencel, "Influence of tea waste concentration in the physical, mechanical and thermal properties of brick clay mixtures," Construction and Building Materials, vol. 217, pp. 592-599, 2019.

[35] S. H. Jakhrani, H. G. Kim, I. K. Jeon, and J. S. Ryou, "Effect of saturated tea waste and perlite particles on early age hydration of high-strength cement mortars," Materials, vol. 12, no. 14, p. 2269, 2019.

[36] T. Kumar and K. Verma, "A theory based on conversion of RGB image to gray image," International Journal of Computer Application, vol. 7, no. 2, pp. 7-10, 2010.

[37] K. Bhargavi and S. Jyothi, "A survey on threshold based segmentation technique in image processing," International Journal of Innovative Research and Development, vol. 3, no. 12, pp. 234-239, 2014.

[38] H. Tang, R. Ni, Y. Zhao, and X. Li, "Median filtering detection of small-size image based on CNN," Journal of Visual Communication and Image Representation, vol. 51, pp. 162168, 2018.

[39] L. S. Liebovitch and T. Toth, "A fast algorithm to determine fractal dimensions by box counting," Physics Letters A, vol. 141, no. 8-9, pp. 386-390, 1989. 